\title{
Short communication: The effect of an exogenous enzyme with amylolytic activity on gas production and in vitro rumen starch degradability of small and large particles of corn or barley meals
}

\author{
A. Gallo, ${ }^{*}$ G. Giuberti, ${ }^{*}$ S. Duval, $†$ M. Moschini, ${ }^{*}$ and F. Masoero*1 \\ *Feed \& Food Science and Nutrition Institute, Faculty of Agriculture, Università Cattolica del Sacro Cuore, 29100 Piacenza, Italy \\ †DSM Nutritional Products, 1 Bd d'Alsace, Village-Neuf. BP170, France
}

\begin{abstract}
The objective of this study was to evaluate the effect of exogenous amylase supplementation on gas production and on in vitro rumen starch degradability (IVSD) of different sized particles of corn and barley meals ( $\mathrm{Cm}$ and $\mathrm{Bm}$, respectively). An aqueous liquid amylase formulation from Bacillus licheniformis was tested at 3 enzyme doses (EnzD; 0, 300 and 1,500 kilo novo units/kg of dry matter) on small $(<750 \mu \mathrm{m})$ and large $(\geq 750 \mu \mathrm{m})$ particle size (PS) of $\mathrm{Cm}$ and $\mathrm{Bm}$. Data were analyzed according to a randomized complete block design with a factorial arrangement of treatments; the main tested effects were PS, EnzD, and their interaction. Fermentation run entered in the model as random effect. The mixed rumen fluid was collected from 2 rumen-fistulated Holstein dry dairy cows fed at maintenance (forage:concentrate ratio of 80:20; $12 \%$ crude protein; $55 \%$ amylase-treated neutral detergent fiber). Small particles of both $\mathrm{Cm}$ and $\mathrm{Bm}$ had a greater rate of fermentation and shorter lag time than large particles. The rate of starch degradation was greater for small than for large particles of Bm, being 0.187 and $0.125 \mathrm{l} / \mathrm{h}$, respectively. Conversely, the rate of starch degradation of $\mathrm{Cm}$ averaged $0.0631 / \mathrm{h}$ and was similar among treatments. Enzyme supplementation tended to reduce lag time and to increase rate of fermentation for both PS of $\mathrm{Cm}$ and $\mathrm{Bm}$, with a more pronounced effect for small PS. A limited EnzD effect was measured for IVSD data and rate of starch degradation; PS influenced fermentation parameters and the magnitude of starch degradation more than EnzD. Supplementation with exogenous amylase influenced the rumen fermentation pattern of small and large PS of $\mathrm{Cm}$ and Bm, even if the effect of the enzyme supplementation differed according to the PS of cereal meals.
\end{abstract}

Received June 3, 2015.

Accepted October 1, 2015.

${ }^{1}$ Corresponding author: francesco.masoero@unicatt.it
Key words: exogenous amylase, particle size, gas production, starch degradation

\section{Short Communication}

Cereals represent the primary starch source in ruminant diets and relatively high levels of dietary starch are typically used to meet the energy requirements of high-producing lactating dairy cows (Giuberti et al., 2014). A greater understanding of starch digestion, along with variation in raw ingredient composition and the historic increase in cereal prices (FAO, 2015), has increased interest in using exogenous amylase in dairy cow diets (Tricarico et al., 2007), even if possible benefits in increasing rumen starch digestibility should be evaluated against potential digestive disorders in cattle (Yang and Beauchemin, 2006). Variable responses following enzyme supplementation have been reported. In particular, Gencoglu et al. (2010) reported a greater conversion of feed to milk in dairy cows fed reducedstarch diets (dietary starch content from 27.1 to $20.7 \%$ DM) with inclusion of a commercial exogenous amylase. Ferraretto et al. (2011) and Weiss et al. (2011), carrying out in vivo experiments, described marginal beneficial effects due to the addition of the same commercial enzyme in normal or reduced-starch diets (dietary starch content of 27 to $31 \%$ or 21 to $26 \%$ DM, respectively). As hypothesized by Weiss et al. (2011), a potential reason for the lack of effect of amylolytic enzyme supplementation could be related to the effect of particle size (PS) of the grains, hiding possible effects resulting from the enzyme supplementation.

Because no information is currently available on the effect of exogenous amylase supplementation in relation to different PS of cereal grains, the current study was designed to evaluate the effects of enzyme supplementation on gas production and in vitro rumen starch degradability (IVSD) of small $(<750 \mu \mathrm{m})$ and large $(\geq 750 \mu \mathrm{m})$ particles of corn and barley meals $(\mathbf{C m}$ and $\mathrm{Bm}$, respectively). These in vitro rumen-based methods are useful to evaluate potential digestibility of nutrients 
in the different compartments of the gastrointestinal tract of animals (Giuberti et al., 2014).

Three 5 -kg batches of dry whole-kernel corn $(\mathrm{Cm})$ and dry, hull-less whole-kernel barley $(\mathrm{Bm})$ were collected over 3 wk (one batch each week) from the same feedstock grains stored in 2 silos on the CERZOO Research and Experimental Dairy Farm (San Bonico, Italy). Subsamples $(1 \mathrm{~kg})$ of $\mathrm{Cm}$ and $\mathrm{Bm}$ were separately processed through a 2-mm sieve using a Retsch type ZM100 centrifugal grinding mill (Retsch, Haan, Germany). Representative aliquots $(200 \mathrm{~g})$ of the resulting products were run through a sieve shaker (RX-29-E-110, W. S. Tyler Co., Mentor, $\mathrm{OH}$ ) equipped with a $750-\mu \mathrm{m}$ sieve for $10 \mathrm{~min}$. Particles were thus divided into small $(<750$ $\mu \mathrm{m})$ and large $(\geq 750 \mu \mathrm{m})$ PS. Another portion (500 g) of each of the 3 batches of cereal grain was ground through a $1-\mathrm{mm}$ screen and stored for further analysis, as previously described by Gallo et al. (2013). Samples were assayed according to AOAC International (2000) methods for DM, CP, ether extract, and ash contents (methods 930.15, 976.05, 954.02 without acid hydrolysis, and 942.05, respectively). Total starch content was determined by polarimetry (Polax 2L, Atago, Tokyo, Japan). Amylase-treated NDF (aNDF), analyzed by using heat-stable amylase and sodium sulfite and not corrected for residual ash, and the ADF contents of samples were determined as described by Van Soest et al. (1991). All analyses were assayed in duplicate for each cereal batch (except for DM determination) and values were averaged as analytical replicates.

An aqueous liquid amylase formulation from Bacillus licheniformis (DSM 21564; Ronozyme RumiStar 240L, DSM Nutritional Products, Basel, Switzerland; Novozyme A/S, Bagsvaerd, Denmark) with a minimum declared amylase activity of 240 kilo novo units $(\mathbf{K N U}) / \mathrm{g}$ (EFSA, 2012) was tested at 3 enzyme doses (EnzD): 0, 300 , and $1,500 \mathrm{KNU} / \mathrm{kg}$ of $\mathrm{DM}$, corresponding, respectively, to approximately $0,0.28$, and $1.38 \mathrm{mg}$ per syringe or $0,0.43$, and $2.16 \mathrm{mg}$ per bottle for $\mathrm{Cm}$, and 0 , 0.50 , and $2.50 \mathrm{mg}$ per bottle for Bm of the commercial product) on the 2 PS $(<750$ and $\geq 750 \mu \mathrm{m})$ produced from each batch of $\mathrm{Cm}$ and $\mathrm{Bm}$. Specific amounts of the commercial product were previously weighed into 3 -mL graduated plastic syringes and then individually injected to each corresponding syringe or bottle before addition of diluted rumen fluid.

Samples were incubated with diluted rumen fluid to measure rumen fermentation according to gas production as described by Menke and Steingass (1988). Rumen liquor was collected from the rumen of 2 fistulated Holstein dry dairy cows $(625 \pm 10 \mathrm{~kg}$ of BW, $38 \pm 0.1$ mo old) fed at maintenance (NRC, 2001) with a TMR (12\% CP and $55 \%$ aNDF on a DM basis) composed of grass hay, corn silage, and a protein vitamin mineral supplement $(75,15$, and $10 \% \mathrm{DM}$, respectively). The collected rumen liquor was filtered through 2 layers of cheesecloth before being diluted with buffer (buffer:rumen fluid ratio of 2:1, vol:vol) and saturated with $\mathrm{CO}_{2}$, and then the $\mathrm{pH}$ was corrected to 6.5 to 6.6. At all times, the rumen liquor was maintained in a warm insulated flask and used within 20 min of sampling. In the meantime, $220 \mathrm{mg}$ of each sample to be tested was weighed into a graduated $100-\mathrm{mL}$ glass syringe and $30 \mathrm{~mL}$ of the diluted rumen fluid was added. Syringes were placed vertically in a water bath at $39^{\circ} \mathrm{C}$ and 3 syringes without substrate were used as blanks. Samples were incubated in triplicate in 2 separate runs. Gas production was measured after 1, 2, 4, 6, 8, 12, 24, 48, and $72 \mathrm{~h}$ of incubation. An internal standard was also incubated. A one-pool exponential model was adopted (Wang et al., 2013) to fit gas production data and obtain curve parameters - final volume $(\mathbf{V f}, \mathrm{mL} / \mathrm{g}$ of $\mathrm{OM})$, rate of gas production $(\mathbf{k d}, 1 / \mathrm{h})$, and lag time (h) - for each individual syringe.

The IVSD was evaluated by an in vitro method proposed by Sveinbjörnsson et al. (2007) and modified by Gallo et al. (2014). To incubate a similar amount of starch (i.e., $250 \mathrm{mg}$ ), each sample was weighed into 125$\mathrm{mL}$ glass bottles equipped with rubber stoppers. Then, the samples were gassed with $\mathrm{CO}_{2}$ and incubated with $30 \mathrm{~mL}$ of the buffered rumen fluid (described above) at $39^{\circ} \mathrm{C}$ in a shaking water bath at $50 \mathrm{rpm}$. Blanks and internal standard (Gelose 80 maize starch; Penford Food Ingredients Co., Centennial, CO) were also incubated. The IVSD was calculated as the ratio between the amount of starch that disappeared after 2, 4, 7, and $72 \mathrm{~h}$ of incubation and the amount of starch in the sample before incubation, after correction for blanks (Sveinbjörnsson et al., 2007). Samples were analyzed in triplicate in 2 separate runs. Three bottles were used for each time point. At each experimental time, bottles were plunged into a bath of ice to stop fermentation, and the remaining starch was quantified by a 2 -step enzymatic (i.e., $\alpha$-amylase and amyloglucosidase hydrolysis) approach (Gallo et al., 2014).

The rate of starch degradation (kd starch, 1/h) was calculated from IVSD data measured after 2,4 , and 7 $\mathrm{h}$ of rumen incubation, using a first-order exponential model and assuming a constant lag time of $0.5 \mathrm{~h}$ and a constant amount of indigestible starch equal to $0.5 \%$ starch (IVSD values evaluated after $72 \mathrm{~h}$ of rumen incubation were lower than $1 \%$ for all samples).

Using the MIXED procedure of SAS (SAS Institute, 2003), ANOVA was conducted using a completely randomized block design for each tested meal (i.e., Cm or $\mathrm{Bm})$ with a factorial arrangement of treatments. 
Fermentation run block effect entered in the model as random. Fermentation parameters and IVSD data were analyzed with the following model:

$$
\begin{gathered}
Y_{i j k m}=\mu+B_{i}+P_{j}+E_{j} D_{k} \\
+(P S \times E n z D)_{j k}+e_{i j k m},
\end{gathered}
$$

where $\mathrm{Y}_{\mathrm{ijkm}}=$ the response variable; $\mu=$ overall mean; $\mathrm{B}_{\mathrm{i}}=$ random block effect of fermentation run $(\mathrm{i}=2)$; $\mathrm{PS}_{\mathrm{j}}=$ fixed effect of particle size $(\mathrm{j}=2) ; \mathrm{EnzD}_{\mathrm{k}}=$ fixed effect of enzyme dose $(\mathrm{k}=3) ;(\mathrm{PS} \times \mathrm{EnzD})_{\mathrm{jk}}=$ interaction; and $\mathrm{e}_{\mathrm{ijkm}}=$ random residual error. When the EnzD effect was significant and in the absence of interactions, the linear and quadratic effects of EnzD were evaluated by orthogonal contrasts. The IML procedure of SAS (SAS Institute, 2003) was used to generate linear and quadratic contrast coefficients. Significance was declared at $P<0.05$, and a tendency was declared at $P<0.10$.

The chemical composition of the 2 original cereal meals was typical of their type, with starch and aNDF contents of $72.2 \pm 2.0 \%$ and $9.5 \pm 0.3 \%$ for $\mathrm{Cm}$ and 62.4 $\pm 1.7 \%$ and $13.3 \pm 0.7 \%$ for $\mathrm{Bm}$, respectively (Table 1). Based on the results of the proximate analysis, the homogeneity of the various batches before and after grinding was adequate, with batch variance not differing from analytical variance for all parameters analyzed in $\mathrm{Cm}$ and $\mathrm{Bm}$.

Table 1. Chemical composition (\% of DM, unless otherwise noted;

\begin{tabular}{|c|c|c|c|}
\hline \multirow[b]{2}{*}{ Item } & \multirow{2}{*}{$\begin{array}{c}\text { Original } \\
\text { meals } \\
(\mathrm{n}=3)\end{array}$} & \multicolumn{2}{|c|}{ Particle size ${ }^{1}$} \\
\hline & & $\begin{array}{c}\text { Small } \\
(\mathrm{n}=3)\end{array}$ & $\begin{array}{c}\text { Large } \\
(\mathrm{n}=3)\end{array}$ \\
\hline \multicolumn{4}{|l|}{ Corn } \\
\hline aNDF $^{2}$ & $9.5 \pm 0.3$ & $9.3 \pm 0.3$ & $9.5 \pm 0.2$ \\
\hline $\mathrm{ADF}$ & $3.8 \pm 0.1$ & $3.7 \pm 0.1$ & $3.8 \pm 0.1$ \\
\hline $\mathrm{CP}$ & $8.6 \pm 0.1$ & $8.6 \pm 0.1$ & $8.7 \pm 0.1$ \\
\hline Ether extract & $4.2 \pm 0.1$ & $4.1 \pm 0.1$ & $4.2 \pm 0.1$ \\
\hline Ash & $1.8 \pm 0.1$ & $1.8 \pm 0.1$ & $1.9 \pm 0.1$ \\
\hline Starch & $72.2 \pm 2.0$ & $72.3 \pm 2.6$ & $72.1 \pm 1.5$ \\
\hline Relative amount ${ }^{3}(\%)$ & & $36 \pm 1.8$ & $64 \pm 1.8$ \\
\hline \multicolumn{4}{|l|}{ Barley } \\
\hline $\mathrm{aNDF}^{2}$ & $13.3 \pm 0.7$ & $13.4 \pm 0.7$ & $13.1 \pm 0.6$ \\
\hline $\mathrm{ADF}$ & $4.3 \pm 0.2$ & $4.3 \pm 0.2$ & $4.4 \pm 0.1$ \\
\hline $\mathrm{CP}$ & $12.5 \pm 0.3$ & $12.6 \pm 0.3$ & $12.3 \pm 0.2$ \\
\hline Ether extract & $4.0 \pm 0.1$ & $4.1 \pm 0.1$ & $4.0 \pm 0.1$ \\
\hline Ash & $2.1 \pm 0.2$ & $2.2 \pm 0.2$ & $2.0 \pm 0.2$ \\
\hline Starch & $62.4 \pm 1.7$ & $62.3 \pm 2.0$ & $62.4 \pm 1.5$ \\
\hline Relative amount ${ }^{3}(\%)$ & & $44 \pm 2.4$ & $56 \pm 2.4$ \\
\hline
\end{tabular}
mean $\pm \mathrm{SD}$ ) of original meals and small and large particles

Journal of Dairy Science Vol. 99 No. 5, 2016
Typically, cereal grains are physically processed through a grinder or roller before utilization in animal diets (Giuberti et al., 2014), with their potential digestion usually related to the extent and working conditions applied during processing (Hoffman et al., 2012). Greater lag time $(P<0.01)$ and lower $\mathrm{kd}(P$ $<0.01)$ values were measured in large compared with small particles in both $\mathrm{Cm}$ (Table 2) and Bm (Table 3 ). However, lag time decreased differently in small and large particles with EnzD in Cm (PS $\times$ EnzD interaction, $P=0.03)$. Similarly, a PS $\times$ EnzD interaction $(P$ $=0.02$ ) was detectable on 7-h IVSD in both $\mathrm{Cm}$ and $\mathrm{Bm}$. The kd starch of $\mathrm{Cm}$ averaged $0.0631 / \mathrm{h}$ and it was similar among treatments, whereas the kd starch in small particles of $\mathrm{Bm}$ was $50 \%$ greater than that in large particles (i.e., 0.187 and $0.1251 / \mathrm{h}$, respectively; PS effect, $P<0.01)$. Our results confirmed that rumen fermentation and IVSD were inversely related to PS, probably because of the smaller surface area potentially available to bacterial digestion or enzymatic hydrolysis in larger compared with smaller particles (Giuberti et al., 2014). When no differences exist at the chemical level between the tested samples, the mean PS is related to fermentation potential (Hoffman et al., 2012). Likewise, Blasel et al. (2006) reported a reduction in the degree of starch access by $\alpha$-amylase of $26.8 \mathrm{~g} / \mathrm{kg}$ of starch for each $100-\mu \mathrm{m}$ increase in PS in ground corn grains.

Enzyme supplementation influenced gas production kinetics of different particles in $\mathrm{Cm}$ and $\mathrm{Bm}$. In particular, Vf were increased (quadratically in $\mathrm{Cm}$ and linearly in $\mathrm{Bm}$ ) and $\mathrm{kd}$ (linearly for both cereals) by enzyme supplementation (EnzD effect, $P=0.03$ in $\mathrm{Cm} ; P=$ 0.02 in $\mathrm{Bm}$ ), whereas no EnzD effect was reported for kd starch in Cm or Bm. Tricarico et al. (2008) hypothesized that addition of enzyme could stimulate rumen microorganism cross-feeding, thus enhancing the OM fermentation activity of rumen microbiota. Although Rojo et al. (2005) suggested that the addition of amylase from Bacillus licheniformis increased rumen starch digestion in grains as a function of level of enzyme supplementation, under our experimental conditions, PS influenced the magnitude of potential fermentation and IVSD more than EnzD in both substrates, confirming observations reported by Weiss et al. (2011). Supplementation with exogenous amylase modified the rumen fermentation pattern, even if its activity and its effect on nutrient availability varied with the different PS of cereal meals tested.

\section{ACKNOWLEDGMENTS}

This project was supported by the AGROSCENARI project "Adaptation scenarios of Italian agriculture to 
Table 2. Fitted kinetic parameters of gas production and rumen in vitro starch degradation data of small and large particles from corn meal supplemented with an increasing dose of exogenous enzyme (EnzD; 0, 300, or 1,500 kilo novo units/kg of DM)

\begin{tabular}{|c|c|c|c|c|c|c|c|c|c|c|c|c|c|}
\hline \multirow[b]{3}{*}{ Item } & \multicolumn{6}{|c|}{ Particle size $^{1}$} & \multirow[b]{3}{*}{ SEM } & \multirow{2}{*}{\multicolumn{4}{|c|}{$P<$}} & \multirow{2}{*}{\multicolumn{2}{|c|}{ EnzD contrasts }} \\
\hline & \multicolumn{3}{|c|}{ Small } & \multicolumn{3}{|c|}{ Large } & & & & & & & \\
\hline & 0 & 300 & 1,500 & 0 & 300 & 1,500 & & Run & PS & EnzD & $\mathrm{PS} \times \mathrm{EnzD}$ & Linear & Quadratic \\
\hline \multicolumn{14}{|l|}{$\overline{\text { Gas production parameters }^{2}}$} \\
\hline Lag time $(\mathrm{h})$ & 2.3 & 2.2 & 2.2 & 3.1 & 2.9 & 2.8 & 0.1 & 0.99 & $<0.01$ & $<0.01$ & 0.03 & - & - \\
\hline $\mathrm{Vf}(\mathrm{mL} / \mathrm{g}$ of $\mathrm{OM})$ & 337 & 355 & 356 & 365 & 379 & 380 & 7 & 0.11 & $<0.01$ & 0.03 & 0.94 & 0.05 & 0.05 \\
\hline $\mathrm{kd}(1 / \mathrm{h})$ & 0.088 & 0.094 & 0.096 & 0.055 & 0.057 & 0.057 & 0.002 & 0.76 & $<0.01$ & 0.03 & 0.27 & 0.03 & 0.14 \\
\hline \multicolumn{14}{|c|}{ Rumen in vitro starch degradation ${ }^{3}$ data } \\
\hline 2-h IVSD ( $\%$ of starch) & 13.7 & 7.4 & 7.9 & 12.2 & 7.8 & 14.1 & 1.6 & 0.73 & 0.19 & 0.01 & 0.06 & - & - \\
\hline 4-h IVSD (\% of starch) & 16.5 & 11.6 & 14.2 & 13.9 & 12.7 & 9.3 & 2.2 & 0.89 & 0.25 & 0.26 & 0.42 & - & - \\
\hline 7-h IVSD ( $\%$ of starch) & 40.0 & 43.0 & 44.9 & 35.3 & 33.6 & 38.8 & 1.8 & 0.92 & $<0.01$ & 0.73 & 0.02 & - & - \\
\hline kd starch $(1 / \mathrm{h})$ & 0.076 & 0.058 & 0.064 & 0.066 & 0.053 & 0.061 & 0.091 & 0.87 & 0.23 & 0.45 & 0.24 & - & - \\
\hline
\end{tabular}

${ }^{1}$ Small $(<750 \mu \mathrm{m})$ and large $(\geq 750 \mu \mathrm{m})$ particle size (PS).

${ }^{2}$ Gas production parameters: $\mathrm{Vf}=$ final volume; $\mathrm{kd}=$ rate of gas production

${ }^{3} \mathrm{IVSD}=$ in vitro starch degradation; $\mathrm{kd}$ starch $=$ rate of starch degradation, calculated by using a first-order exponential model and assuming a constant lag time of $0.5 \mathrm{~h}$ and a constant amount of indigestible starch equal to $0.5 \%$ starch.

Table 3. Fitted kinetic parameters of gas production and rumen in vitro starch degradation data of small and large particles from barley meal supplemented with an increasing dose of exogenous enzyme (EnzD; 0, 300, or 1,500 kilo novo units/kg of DM)

\begin{tabular}{|c|c|c|c|c|c|c|c|c|c|c|c|c|c|}
\hline \multirow[b]{3}{*}{ Item } & \multicolumn{6}{|c|}{ Particle size ${ }^{1}$} & \multirow[b]{3}{*}{ SEM } & \multirow{2}{*}{\multicolumn{4}{|c|}{$P<$}} & \multirow{2}{*}{\multicolumn{2}{|c|}{ EnzD contrasts }} \\
\hline & \multicolumn{3}{|c|}{ Small } & \multicolumn{3}{|c|}{ Large } & & & & & & & \\
\hline & 0 & 300 & 1,500 & 0 & 300 & 1,500 & & Run & PS & EnzD & PS $\times$ EnzD & Linear & Quadratic \\
\hline \multicolumn{14}{|c|}{ Gas production parameters ${ }^{2}$} \\
\hline Lag time $(\mathrm{h})$ & 1.3 & 1.1 & 1.0 & 2.1 & 2.0 & 2.0 & 0.1 & 0.17 & $<0.01$ & $<0.01$ & 0.16 & $<0.01$ & 0.07 \\
\hline $\mathrm{Vf}(\mathrm{mL} / \mathrm{g}$ of $\mathrm{OM})$ & 294 & 301 & 309 & 334 & 349 & 352 & 5 & $<0.01$ & $<0.01$ & 0.02 & 0.73 & 0.01 & 0.11 \\
\hline $\mathrm{kd}(1 / \mathrm{h})$ & 0.122 & 0.130 & 0.131 & 0.088 & 0.088 & 0.094 & 0.002 & $<0.01$ & $<0.01$ & 0.02 & 0.30 & $<0.01$ & 0.26 \\
\hline \multicolumn{14}{|c|}{ Rumen in vitro starch degradation ${ }^{3}$ data } \\
\hline 2-h IVSD (\% starch) & 31.6 & 22.3 & 24.8 & 17.1 & 28.4 & 23.0 & 7.4 & 0.74 & 0.28 & 0.93 & 0.04 & - & - \\
\hline 4-h IVSD (\% starch) & 38.1 & 39.8 & 41.1 & 29.2 & 33.9 & 23.2 & 6.1 & 0.87 & $<0.01$ & 0.82 & 0.33 & - & - \\
\hline 7-h IVSD (\% starch) & 71.6 & 76.9 & 72.3 & 50.9 & 53.1 & 55.5 & 2.6 & 0.91 & $<0.01$ & 0.04 & 0.02 & - & - \\
\hline $\mathrm{kd} \operatorname{starch}(1 / \mathrm{h})$ & 0.200 & 0.182 & 0.179 & 0.117 & 0.139 & 0.119 & 0.125 & 0.85 & $<0.01$ & 0.64 & 0.21 & - & - \\
\hline
\end{tabular}

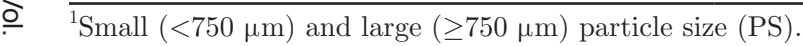

$\circledast{ }^{2}$ Gas production parameters: $\mathrm{Vf}=$ final volume; $\mathrm{kd}=$ rate of gas production

Z $\quad{ }^{3}$ IVSD $=$ in vitro starch degradation; $\mathrm{kd}$ starch = rate of starch degradation, calculated by using a first-order exponential model and assuming a constant lag time of 0.5 h and a or constant amount of indigestible starch equal to $0.5 \%$ starch. 
climate change" of MIPAAF (Ministero delle politiche agricole alimentari e forestali, Italy) and by DSM Nutritional Products (Basel, Switzerland).

\section{REFERENCES}

AOAC International. 2000. Official Methods of Analysis. 17th ed. Association of Official Analytical Chemists, Gaithersburg, MD.

Blasel, H. M., P. C. Hoffman, and R. D. Shaver. 2006. Degree of starch access: An enzymatic method to determine starch degradation potential of corn grain and corn silage. Anim. Feed Sci. Technol. 128:96-107.

EFSA. 2012. Scientific Opinion on the safety and efficacy of Ronozyme RumiStar (alpha-amylase) as a feed additive for dairy cows. EFSA (European Food Safety Authority) Panel on Additives and Products or Substances used in Animal Feed (FEEDAP). EFSA J. 10:2777.

FAO (Food and Agriculture Organization of the United Nations). 2015. Cereals price index. Accessed Sep. 15, 2015. http://www.fao. org/worldfoodsituation/foodpricesindex/en/.

Ferraretto, L. F., R. D. Shaver, M. Espineira, H. Gencoglu, and S J. Bertics. 2011. Influence of a reduced-starch diet with or without exogenous amylase on lactation performance by dairy cows. J. Dairy Sci. 94:1490-1499.

Gallo, A., G. Giuberti, F. Masoero, A. Palmonari, L. Fiorentini, and M. Moschini. 2014. Response on yield and nutritive value of two commercial maize hybrids as a consequence of a water irrigation reduction. Ital. J. Anim. Sci. 13:594-599.

Gallo, A., M. Moschini, C. Cerioli, and F. Masoero. 2013. Use of principal component analysis to classify forages and predict their calculated energy content. Animal 7:930-939.

Gencoglu, H., R. D. Shaver, W. Steinberg, J. Ensink, L. F. Ferraretto, S. J. Bertics, J. C. Lopes, and M. S. Akins. 2010. Effect of feeding a reduced-starch diet with or without amylase addition on lactation performance in dairy cows. J. Dairy Sci. 93:723-732.

Giuberti, G., A. Gallo, F. Masoero, L. F. Ferraretto, P. C. Hoffman, and R. D. Shaver. 2014. Factors affecting starch utilization in large animal food production system: A review. Starch 66:72-90.
Hoffman, P. C., D. R. Mertens, J. Larson, W. K. Coblentz, and R. D. Shaver. 2012. A query for effective mean particle size in dry and high-moisture corns. J. Dairy Sci. 95:3467-3477.

Menke, K. H., and H. Steingass. 1988. Estimation of the energetic feed value obtained from chemical analysis and gas production using rumen fluid. Anim. Res. Dev. 28:7-55.

NRC. 2001. Nutrient Requirements of Dairy Cattle. 7th rev. ed. Natl. Acad. Press, Washington, DC.

Rojo, R., G. D. Mendoza, S. S. González, L. Landois, R. Bárcena, and M. M. Crosby. 2005. Effects of exogenous amylases from Bacillus licheniformis and Aspergillus niger on ruminal starch digestion and lamb performance. Anim. Feed Sci. Technol. 123-124:655-665.

SAS Institute. 2003. Guide for Personal Computers. Version 9.2. SAS Inst. Inc., Cary, NC.

Sveinbjörnsson, J., M. Murphy, and P. Udén. 2007. In vitro evaluation of starch degradation from feeds with or without various heat treatments. Anim. Feed Sci. Technol. 132:171-185.

Tricarico, J. M., J. D. Johnston, and K. A. Dawson. 2008. Dietary supplementation of ruminant diets with an Aspergillus oryzae $\alpha$-amylase. Anim. Feed Sci. Technol. 145:136-150.

Tricarico, J. M., J. D. Johnston, K. A. Dawson, K. C. Hanson, K. R. McLeod, and D. L. Harmon. 2007. The effects of an Aspergillus oryzae extract containing alpha-amylase activity on ruminal fermentation and milk production in lactating Holstein cows. Anim. Sci. 81:365-374.

Van Soest, P. J., J. B. Robertson, and B. A. Lewis. 1991. Methods for dietary fiber, neutral detergent fiber, and nonstarch polysaccharides in relation to animal nutrition. J. Dairy Sci. 74:3583-3597.

Wang, M., X. Z. Sun, S. X. Tang, Z. L. Tan, and D. Pacheco. 2013 Deriving fractional rate of degradation of logistic-exponential (LE) model to evaluate early in vitro fermentation. Animal 7:920-929.

Weiss, W. P., W. Steinberg, and M. A. Engstrom. 2011. Milk production and nutrient digestibility by dairy cows when fed exogenous amylase with coarsely ground dry corn. J. Dairy Sci. 94:2492-2499.

Yang, W. Z., and K. A. Beauchemin. 2006. Increasing the physically effective fiber content of dairy cow diets may lower efficiency of feed use. J. Dairy Sci. 89:2694-2704. 